\title{
Creation and study of formulations as inhibitors of metal corrosion and scaling for stabilization water treatment in water utilization systems (a review)
}

\author{
N.V. Tsirulnikova, ${ }^{1}$ Ya.V. Bolt, ${ }^{1}$ E.S. Dernovaya, ${ }^{1}$ B.N. Driker ${ }^{2}$ \\ and T.S. Fetisova ${ }^{1}$ \\ ${ }^{1}$ The Federal State Unitary Enterprise "The State Scientific Research Institute of Chemical \\ Reagents and High Purity Chemical Substances" (FSUE “IREA”), \\ Bogorodskiy Val Street, 3, 107076 Moscow, Russian Federation \\ ${ }^{2}$ Ural State Forest Engineering University (USFEU), Sibirsky Trakt, 37, \\ 620032 Yekaterinburg, Russian Federation \\ E-mail:nv.tsir@mail.ru
}

\begin{abstract}
This review summarizes studies for the past 5 years aimed at creation of efficient organophosphonate reagents for the stabilization water treatment aimed at preventing metal corrosion and scaling in water utilization systems.
\end{abstract}

Keywords: stabilization water treatment, scaling and corrosion inhibitors, efficiency, complexons, organophosphonates, hydroxyethylidene diphosphonic acid, complexes, zinc(II) salts and magnesium(II) salts, polymeric reagents, formulations.

Received: December 17, 2015. Published: February 6, 2016.

doi: $\underline{10.17675 / 2305-6894-2016-5-1-6}$

\section{Introduction}

Successful operation of closed and zero-discharge drainage water utilization systems ensuring efficient use of water resources and reduction of ecological tension in the environment is achieved in most cases by stabilization treatment of water circulating in these systems by adding chemical reagents, namely, inhibitors that prevent adverse processes of metal corrosion, mineral salt deposition, and biological fouling ${ }^{1}$ in pipelines and process equipment.

This water treatment by reagents is the most efficient and affordable method due to insignificant investments for its implementation: chemical preparation and injection units are simple and reliable in use.

Since the 80 s of the past century, the use of organophosphonates (OP) as corrosion and scale inhibitors became one of the predominant approaches in reagent treatment. The trends in the development and application of OP until 2009 have been considered in detail earlier [1].

\footnotetext{
${ }^{1}$ Biofouling inhibitors are not considered in this review.
} 
The organophosphonates and OP-based formulations most common in water treatment as scale and corrosion inhibitors were identified by reviewing the results of studies. They include hydroxyethylidene diphosphonic acid (HEDP), HEDP-based derivatives and compounds, as well as reagents of OP series containing no HEDP, including reagents based on polymers and aliphatic amines (ethylenedi-, diethylenetri-, hexamethylenediamines), and others.

The subsequent years were not an exception.

Below we present the current tendencies in studies within the past 5 years dedicated to in-depth investigations of proven reagents and to the preparation of new OPs and modification of known ones for creation of efficient multipurpose inhibitors.

It should be noted that generally, the known practically valuable OP and their formulations are thoroughly studied as corrosion and scale inhibitors. New similar reagents are described in but a few publications. Modern methods are widely used in the studies, including potentiodynamic polarization methods, scanning electron microscopy (SEM), energy dispersive spectroscopy (EDS), X-ray photoelectron spectroscopy (XPS), electrical impedance spectroscopy (EIS), Fourier-transform infrared spectroscopy (FTIR), atomic force microscopy (AFM), and inductively coupled plasma method (ICP).

\section{Hydroxyethylidene diphosphonic acid, HEDP-based derivatives and formulations as scale and corrosion inhibitors}

HEDP, individually or in formulations, remains a very popular reagent for stabilization water treatment in water utilization systems at various industrial enterprises, large and small power producing companies, and housing and communal services.

For example, a formulation was suggested [2] containing $60 \%$ of HEDP and $40 \%$ of a newly synthesized phosphonocarboxylic acid (PCA) that inhibits calcium carbonate deposition by $100 \%$ and manifests a synergistic effect. A formulation of $60 \%$ PCA and $40 \%$ phosphonobutanetricarboxylic acid (PBTC) has a similar effect. A formulation of PCA (40\%), PBTC (32\%), and HEDP (24\%) complemented with zinc(II) acetate inhibits metal corrosion by $92.22 \%$ and calcium(II) phosphate deposition by $90.42 \%$.

Researchers continue to pay much attention to the HEDP zinc complex due to its high efficiency as a corrosion inhibitor of metals in the water utilization equipment, despite the fact that the use of $\mathrm{Zn}$ (II) for these purposes is strictly limited.

At the same time, interest not only in theindividual ZnHEDP complex, but also in multicomponent formulations, both based on ZnHEDP and on other complexes of $\mathrm{Zn}$ (II) with OP, remains considerable.

To obtain aqueous solutions of zinc complexes, the solubility of a $\mathrm{Zn}$ (II) salt in solutions of ligands was studied [3]. The Zn (II) salt was found to less soluble in a HEDP aqueous solution than in a multicomponent composition containing nitrilotrimethylphosphonic acid (NTP). According to [3], the results obtained are interesting for further search for multicomponent formulations based on aqueous solutions of zinc complexes. 
Simultaneously, studies of the molecular structure of ZnHEDP still continue. New data on the structure of the complex obtained from XPS data were compared to known [46] absorption IR spectra of the complex [7]. Based on the results [7], it was found that upon coordination of a phosphonic group by $\mathrm{Zn}(\mathrm{II})$, the localized PO $\pi$-bond remains unchanged, there is no third order symmetry axis of the phosphonic group, and $\mathrm{Zn}$ (II) in the complex occupies positions with different types of coordination by phosphonic groups: intermolecular (I) and intramolecular (II).

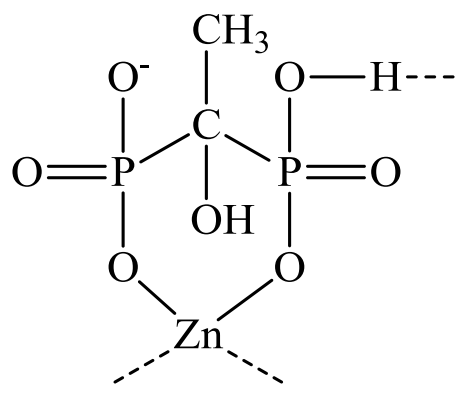

I

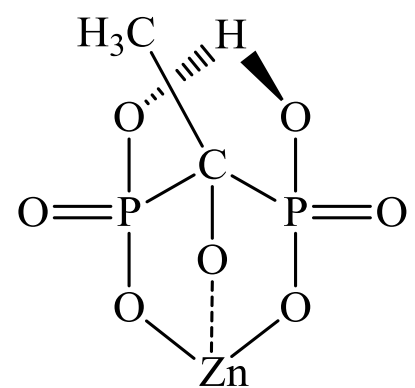

II

Studies of the behavior of ZnHEDP as a corrosion inhibitor on the surface of carbon steel continue as well [8]. In this case, it has been proved that strong covalent bonds $\mathrm{Zn}-$ $\mathrm{O}-\mathrm{P}-\mathrm{Fe}$ are formed. On heating, the $\mathrm{C}-\mathrm{P}$ bond in HEDP breaks to release the carboncontaining moiety. The $\mathrm{Zn}-\mathrm{O}-(\mathrm{P}-\mathrm{O})-\mathrm{Fe}$ bonds break at $525 \mathrm{~K}$. XPS was used as the main research method.

Though the HEDP-zinc complex and similar complexes with various OPs have been known as corrosion inhibitors for almost 30 years, studies of these reagents continue in order to expand their use in metal corrosion prevention.

For example, the efficiency of ZnHEDP was studied using corrosion indicators, and for comparison, that of known inhibitors: IOMS-1, HEDP itself, PAPh-13A (NTP aqueous solution, methyliminodiphosphonic acid (MIDP), and polyaminopolymethylphosphonates), as corrosion inhibitors for internal pipe surfaces in a hot water supply system [9]. These OPs were found to inhibit corrosion in deaerated water, but their efficiency is much lower than that of ZnHEDP.

Based on these results, a water treatment method was implemented in a similar system.

Along with the consumer properties of HEDP providing a successful use of the reagent for stabilization water treatment, the physicochemical properties of HEDP are still being studied. The authors [10] have studied the HEDP effect on the solubility of calcite surfaces using a modern physical and chemical method based on a scanning atomic force microscope. On the basis of the study results, the presence of HEDP in solution was proved to change the water exchange frequency in the $\mathrm{Ca}$ (II) hydration shell. The formation of $\mathrm{CaCH}_{3} \mathrm{C}(\mathrm{OH})\left(\mathrm{PO}_{3} \mathrm{H}\right)_{2} \cdot 2 \mathrm{H}_{2} \mathrm{O}$ complex on calcite surface was detected. 
Publications for the past 5 years demonstrate the interest of researchers in HEDP as a basis for efficient reagents preventing salt deposition and metal corrosion for stabilization water treatment in water utilization systems.

\section{Reagents in organophosphate series containing no HEDP}

\section{Nitrilotri(methylphosphonic acid) and formulations based thereon}

In recent years, studies of proven and known inhibitors - complexons in the series of nitrogen-containing phosphonic acids, such as NTP [ethylenediaminetetra- (EDTP), diethylenetriaminepenta- (DTPP), hexamethylenediaminetetra- (HMDTP), methylphosphonic acids, etc.], and their formulations - have been undergoing thorough studies [11-33].

The effect of ultrasonic irradiation on calcite growth in the presence of NTP as a scale inhibitor has been studied for the first time [11]. The inhibitive activity of NTP is greatly reduced under the conditions of this experiment. At the same time, the radiation increases twice the volume rate of calcite crystal growth, and its restoration by subsequent inhibition slows down significantly compared to a blank experiment. The results obtained, according to [11], should be explained, on the one hand, by the physical effect of irradiation that causes destruction and abrasion of defective crystals that would increase under ordinary conditions. On the other hand, a chemical effect associated with NTP destruction under irradiation plays an important role in the process and results in loss of phosphonic groups, as testified by a mass spectroscopic analysis of irradiated NTP solutions. As a consequence, the inhibitor loses activity.

Loss of activity also results from successive replacement of methylphosphonic groups in NTP with acetate ones in the series of nitrilediphosphonic acetic (NDPA), nitrilephosphonic diacetic (NPDA), and nitrilotriacetic (NTA) acids by the scheme:

$$
\begin{aligned}
& \mathrm{N}\left[\mathrm{CH}_{2} \mathrm{P}(\mathrm{O})(\mathrm{OH})_{2}\right]_{3} \rightarrow \mathrm{N}\left[\mathrm{CH}_{2} \mathrm{P}(\mathrm{O})(\mathrm{OH})_{2}\right]_{2} \mathrm{CH}_{2} \mathrm{COOH} \rightarrow \\
& \rightarrow \mathrm{N}\left[\mathrm{CH}_{2} \mathrm{P}(\mathrm{O})(\mathrm{OH})_{2}\right]\left(\mathrm{CH}_{2} \mathrm{COOH}\right)_{2} \rightarrow \mathrm{N}\left(\mathrm{CH}_{2} \mathrm{COOH}\right)_{3}
\end{aligned}
$$

The efficiencies of the ligands considered form the sequence NTP $>$ NDPA $>$ NPDA $>$ NTA [12]. Similar results were obtained by Russian scientists in the 80 s of the past century [13].

Researchers show high interest in NTP due to its corrosion-inhibiting activity and the budiness interest in this reagent in comparison with other phosphonic acids [14].

In order to elucidate the mechanism of NTP impact on metal surfaces reducing the corrosion rate, modern analytical methods were used, including SEM, EDS and XPS [14].

The fact that various concentrations of NTP affect a carbon steel plate after dipping it into $1 \mathrm{M} \mathrm{HCl}$ solution at $30^{\circ} \mathrm{C}$ for $24 \mathrm{~h}$ has been confirmed by the authors earlier by measuring the mass loss of the plate [15], as well as by analysis of the working solution after the experiment by ICP method [14].

As shown in Table 1, NTP inhibits carbon steel corrosion under the test conditions, reaching a maximum effect of $96.71 \%$ at a reagent concentration of $0.5 \mathrm{M}$. At the same 
time, the phosphorus concentration decreases from 465 to $389.65 \mathrm{mg} / \mathrm{l}$, and iron concentration in the solution decreases significantly as well (from 40.01 to $148.3 \mathrm{mg} / \mathrm{L}$ ).

Table 1. Corrosion parameters obtained from measurements of weight loss of carbon steel plates immersed in $1 \mathrm{M} \mathrm{HCl}$ in the presence of various NTP concentrations at $30^{\circ} \mathrm{C}$

\begin{tabular}{cccc}
\hline Inhibitor & $\begin{array}{c}\text { Inhibitor concentration } \\
(\mathbf{M})\end{array}$ & $\begin{array}{c}\text { Corrosion rate } \\
\left(\mathbf{m g} \cdot \mathbf{c m}^{-\mathbf{2}} \cdot \mathbf{h}^{\mathbf{- 1}}\right)\end{array}$ & Protection degree (\%) \\
\hline- & - & 4.56 & - \\
\hline $5 \times 10^{-5}$ & 3.81 & 16.44 \\
$1 \times 10^{-4}$ & 3.26 & 28.51 \\
$5 \times 10^{-4}$ & 2.77 & 39.25 \\
& $1 \times 10^{-3}$ & 2.20 & 51.75 \\
& $5 \times 10^{-3}$ & 1.03 & 77.41 \\
& $1 \times 10^{-2}$ & 0.71 & 84.43 \\
NTP & $5 \times 10^{-2}$ & 0.25 & 94.52 \\
& $1 \times 10^{-1}$ & 0.18 & 96.05 \\
& $5 \times 10^{-1}$ & 0.15 & 96.71 \\
\hline
\end{tabular}

The latter circumstance indicates NTP adsorption on carbon steel surface.

Using SEM and EDS, the surface morphology of plates pre-exposed to $1 \mathrm{M}$ hydrochloric acid in the absence and presence of NTP was studied and their chemical analysis was performed. The quality and morphology of corrosion layers were estimated by XPS. The results obtained showed that the impact corrosive solution on the metal decreased the presence of NTP due to a protective adsorbed film of the NTP inhibitor formed on the metal surface.

To enhance the NTP activity as a corrosion inhibitor, an NTP-based formulation containing $\mathrm{Zn}$ (II) and nicotinic acid (NA) was proposed for the first time and studied [16].

To study the impact of the proposed formulation as an inhibitor of carbon steel corrosion in a solution with a low $(200 \mu \mathrm{g} / \mathrm{l})$ chloride content, modern methods were used, including potentiodynamic polarization studies, EIS, FTIR, SEM, XPS, and AFM.

The results obtained have shown that NA is a highly efficient synergistic reagent: in the presence of NTP-Zn(II)-NA formulation (30, 20, and $100 \mu \mathrm{g}$, respectively), inhibition of carbon steel plate corrosion reaches $81.15 \%$ in 1 hour after immersion into solution, whereas the efficiency of an NTP-Zn(II) formulation is only $5.46 \%$ and that of NA is $67.29 \%$. It was also found that the effect of corrosion inhibition increased to $95.53 \%$ in 24 hours of plate immersion. 
The results obtained by the authors [16] using high resolution SEM are shown in Figure 1. As one can see in Figure 1a, metal surface is strongly corroded in the absence of an inhibitor: various corrosion products (Fe oxides) appear on metal, whereas they are absent if the metal is exposed to a solution containing the inhibitor. The latter fact is associated with formation of an inhibiting film on the metal surface that prevents chloride ion penetration from the solution. It has been found that a slight surface inhomogeneity (b) is caused by structural defects and the defective parts are also covered with an inhibiting film.
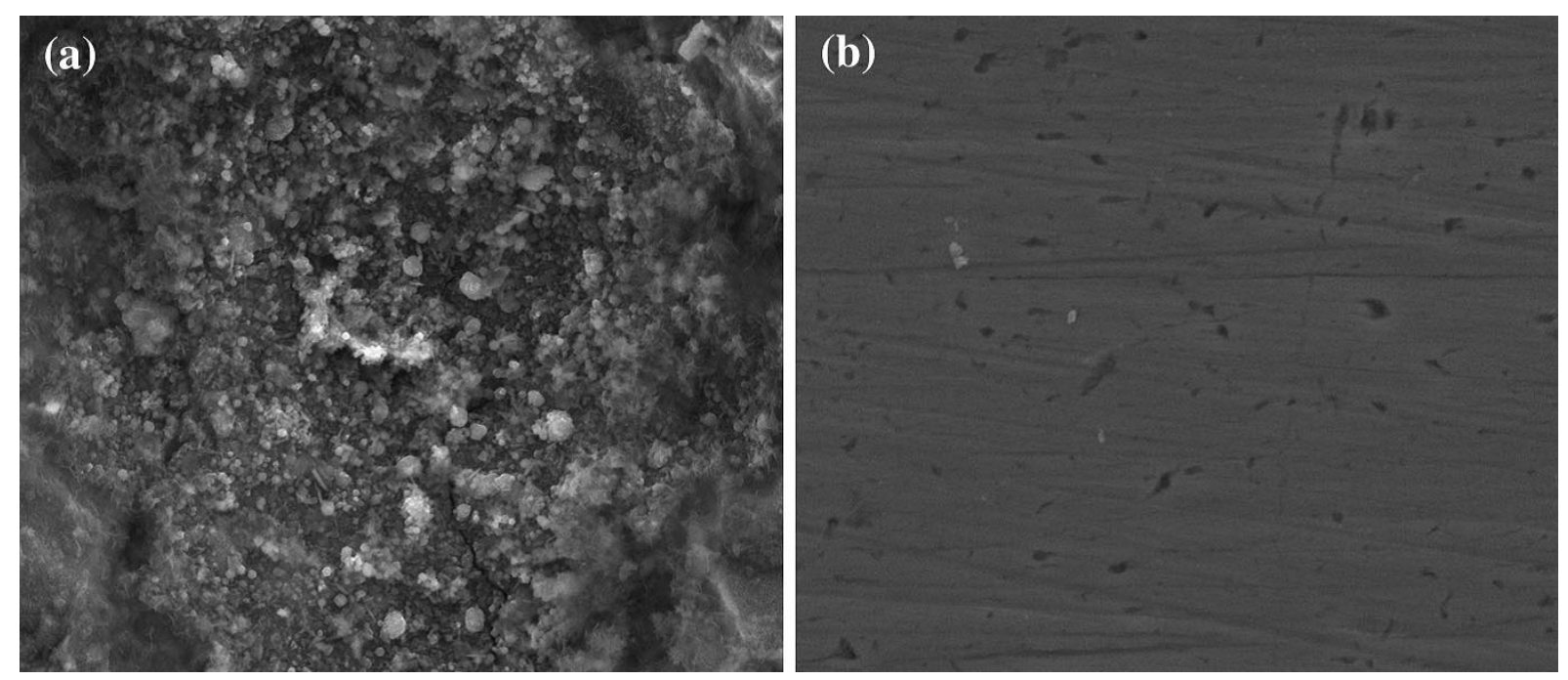

Figure 1. Carbon steel plate surface placed in solution for 7 days in the absence $(a)$ and in the presence $(b)$ of NTP-Zn(II) -NA formulation.

According to XPS, the protective film on the metal-solution boundary contains $\mathrm{Fe}$, $\mathrm{Zn}, \mathrm{P}, \mathrm{N}, \mathrm{C}$ and $\mathrm{O}$ and consists of a multiligand complex containing $\mathrm{Fe}(\mathrm{III}), \mathrm{Zn}(\mathrm{II})-\mathrm{NTP}-$ $\mathrm{NA}, \mathrm{Zn}(\mathrm{OH})_{2}$, and $\mathrm{Fe}_{2} \mathrm{O}_{3}\left[\mathrm{Fe}(\mathrm{OH})_{3}\right]$. The results obtained by the set of methods allowed a likely mechanism of corrosion inhibition with the NTP-Zn(II)-NA formulation to be proposed. The basis of the proposed formulation, according to [16], is a polymeric reagent formed from $\mathrm{Zn}-\mathrm{NTP}$ fragments where $\mathrm{Zn}$ (II) replaces two of six NTP protons, while nitrogen is in the form of betaine.

Publication [17] deals with similar studies of NTP as a corrosion inhibitor. The inhibitor effect was evaluated by mass loss of carbon steel in $1 \mathrm{M}$ hydrochloric acid solution. The studies were carried out using potentiodynamic polarization and electrochemical impedance spectroscopy (EIS). Test results showed that, on the one hand, NTP acts as a mixed inhibitor, and on the other, that corrosion inhibition passes through equivalent cycles. NTP adsorption on carbon steel surface obeys Langmuir isotherms. The calculated value of $G$ indicates that corrosion steel inhibition under the test conditions is determined primarily by NTP physical sorption on the surface, as well as its residence time in the acid solution.

It was also found that in addition to inhibitive activity, NTP has an antibacterial effect against gram-positive and gram-negative bacteria and can be successfully used as a biocide 
in aqueous solutions. The degree of the reagent antibacterial activity is determined by solution $\mathrm{pH}$ and the NTP ionic form corresponding to that $\mathrm{pH}$.

To enhance NTP consumer properties, the authors [18] offer an NTP formulation with a quaternary ammonium base - benzyldimethyltetradecylammonium chloride as a biocide, sodium salt polyaspartate as a scale inhibitor, and a $\mathrm{Zn}$ (II) salt to enhance an anticorrosive activity. The optimum formulation contains 40, 80, 20 and $2 \mathrm{mg}$, respectively, per 1 liter of solution and demonstrates a maximum efficiency in the $\mathrm{pH}$ range of $6.5-9,0$ at $30-70^{\circ} \mathrm{C}$.

Using NTP and $\mathrm{CaSO}_{4}$ as an example, the dependence of the water-inhibitor (complexon) interaction on the efficiency of salt crystallization inhibition was studied for the first time [19]. For this purpose, IR spectra of propylene glycol aqueous solutions were studied in the first water overtone. The degree of $\mathrm{CaSO}_{4}$ inhibition was determined as a function of solution $\mathrm{pH}$ and water content in propylene glycol. Based on this study, it was concluded that the inhibitor efficiency in salt crystallization, a kinetically slow process, greatly depends on water-complexon interaction.

The currently continuing studies of NTP as a multi-purpose inhibitor indicate the practical significance of the reagent.

\section{Polyaminopoly(methylphosphonic acids) and formulations on their basis}

Phosphorus-containing complexons [EDTP, DTPP, HMDTP, triethylenetetraaminohexamethylphosphonic acid (TTHP)] traditionally used for the stabilization water treatment in water utilization systems remain objects of scientists' close attention. The studies aim at expanding the scope of OP use.

EDTP, DTPP, TTHP have been studied as inhibitors of barium sulfate (barytes) sedimentation from brine in oil-field equipment. Barite is formed upon mixing injected water, which is usually rich in sulfates, into well water containing $\mathrm{Ba}$ (II) [20]. The minimum working concentration has been determined for each type of inhibitor depending on the ratio of injected water and water containing $\mathrm{Ba}(\mathrm{II})$, which results in a change $\mathrm{BaSO}_{4}$ saturation coefficient and in precipitation, the $\mathrm{Ca}^{2+} / \mathrm{Mg}^{2+}$ molar ratio, and brine ionic strength.

The results obtained provide very valuable information to elucidate the mechanism of barite inhibition by OP complexons.

Studied are in progress to expand information about the consumer properties of DTPP, a carbonate scale inhibitor with the maximum efficiency. The influence of the reagent concentration on maintaining the $\mathrm{Ca}$ (II) and $\mathrm{Mg}$ (II) concentrations in the solution has been studied [21]. According to the authors, the formation of stable $\mathrm{Ca}$ (II) and $\mathrm{Mg}$ (II) complexes with DTPP should be taken into account to reach a complete picture of the state of carbonates in inhibited solutions, bearing in mind that both cations affect inhibition.

To expand the options for finding new approaches to the scaling inhibition problem, the interaction of DTPP with salts present in aqueous solutions was studied [22].

The effect of $\mathrm{Fe}$ (II, III) ions, divalent ions of $\mathrm{Ca}$ and $\mathrm{Mg}$, and $\mathrm{Na}(\mathrm{I})$ ions on $\mathrm{CaCO}_{3}$ and $\mathrm{BaSO}_{4}$ sedimentation in the absence and presence of scale inhibitors, including DTPP, 
aspartic and polyvinylsulfonic acids, and an inhibitor containing a carboxy and phosphonic groups simultaneously, is presented in [23].

To enhance the DTPP inhibitive activity as a corrosion inhibitor for stainless steel, a formulation of DTPP, a biofilm and Zn(II) sulfate was proposed and studied [24].

It has been shown that this formulation can be successfully recommended for corrosion prevention of water utilization equipment made of stainless steels.

The activity of various OPs, including EDTP, HEDP, and NTP, as inhibitors of calcium sulfate deposition on pipe metal surfaces was studied [12].

The main factors determining the OP inhibitive activity were considered, including the chemical structure, concentration, and reagent residence time in the system, and the relation between these factors and the rate of scale formation were determined. The adsorption of the reagents concerned on a solid phase described by the Langmuir isotherm allows one to predict the critical concentrations above which full inhibition of scale is observed. The OPs studied form the following sequence in terms of efficiency: EDTP > NTP $>$ HEDP.

The results obtained confirmed the efficiency of the OPs studied that was determined previously [25].

Along with EDTP, the effect of HMDTP, octa- and dodecylmethylenetetramethylphosphonic acids on the crystallization of sulfate $\mathrm{Ca}$ (II) dihydrate has been studied [26]. The OPs studied were found to inhibit salt crystallization very efficiently. The inhibitive activity of a reagent is proportional to a number of methylene groups in the organic chain associated with half of methylphosphonic groups. The degree of salt crystallization inhibition was estimated by increase in the induction time and reduction in the crystallization rate. Particle size and crystal morphology were assessed using a particle classifier and scanning electron microscopy. Based on the results obtained, it was found that the OPs studied are efficient inhibitors of $\mathrm{CaSO}_{4} \cdot 2 \mathrm{H}_{2} \mathrm{O}$ deposition. The crystal structure of $\left[\mathrm{Ca}(\mathrm{EDTP}) \mathrm{H}_{2} \mathrm{O}\right] \mathrm{H}_{2} \mathrm{O}$ was described.

A series OPs were studied as inhibitors of calcium carbonate deposition in cooling water systems, such as aliphatic amine derivatives, including EDTP, DTPC, HMDTP, hexamethylenetriaminepentamethylphosphonic (HMTPP) and diaminopolyethertetramethylphosphonic (DPETP) acids, as well as NTP, HEDP and PBTC [27].

The solubility of $\mathrm{Ca}$ (II) complexes with OPs has been determined from empirical data. It decreases in the series HMTPP $>$ DPETP $>$ HMDTP $>$ PBTC $>$ DTPP $>$ EDTP $>$ NTP $>$ HEDP. Polymeric reagents have been proposed as inhibitors of $\mathrm{Ca}$ (II) phosphate deposition that additionally enhance the prevention of $\mathrm{CaCO}_{3}$ deposition. It should be noted that stabilization water treatment properly implemented in the facility and preceded by studies on the selection of a specific inhibitor and its working concentration in real water eliminates the precipitation of $\mathrm{Ca}$ (II) complexes with OPs.

Studies on the creation of high-performance composite corrosion and scale inhibitors using based on HMDTP are still in progress. These studies are focused on HMDTP addition into formulations as a synergistic additive. For this purpose, formulations of 
IOMS-1 (a commercial inhibitor of mineral salts deposition based on NTP and MIDP), HMDTP and $\mathrm{Zn}$ (II) in various amounts were studied [28].

As shown in Figure 2, addition of the HMDTP-Zn formulation $(20 \%$ of the total mass of the target agent) makes it possible to significantly enhance the activity of the initial reagent IOMS-1-Zn as a corrosion inhibitor that is not inferior to HMDTP-Zn in efficiency.

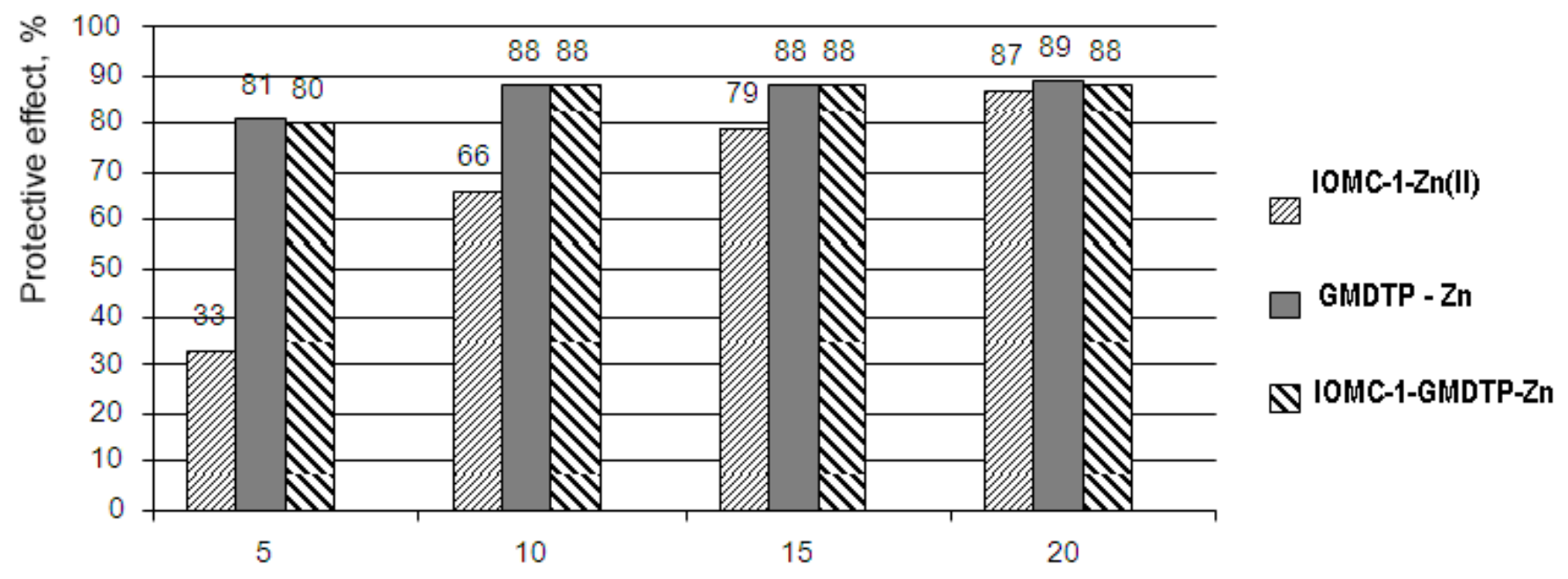

reagent concentration, mgll

Figure 2. Protective effect of St3 steel corrosion inhibition by complexons of $\mathrm{Zn}(\mathrm{II})$ with 1IOMS and GMDTP and their formulations (the corrosion rate in the blank test was $0.18 \mathrm{mpy}$ ).

The maximum ( $90 \%)$ protective effect is achieved at $10 \mathrm{mg} / 1(2 \mathrm{mg} / \mathrm{l}$ based on HMDTP $-\mathrm{Zn}$ ) reagent working concentration in mineralized water.

Increasing requirements to reduce environmental impact restrict the use of $\mathrm{Zn}$ containing OP-based formulations as corrosion inhibitors. In addition, these corrosion inhibitors do not provide the desired effect in the presence of $\mathrm{H}_{2} \mathrm{~S}$ in water utilization systems in oil and gas industry.

It was assumed [29] that OPs and their $\mathrm{Zn}$ (II) free formulations can serve as efficient corrosion inhibitors in hard high-mineralized solutions. In view of this, they studied the inhibition of carbon steel corrosion in hard high-mineralized water by $\mathrm{Mg}$ complexes of OPs (Figure 3). The effect of small $(5 \mathrm{mg} / \mathrm{l}) \mathrm{H}_{2} \mathrm{~S}$ amounts on the protective properties of corrosion inhibitors under these conditions was studied, and in was also demonstrated that the efficiency of Mg-containing $\mathrm{OP}$ formulations in mixtures with catamine $\mathrm{AB}$ and IFHANa-92 in the presence of $\mathrm{H}_{2} \mathrm{~S}$ increased. A distinctive feature of these formulations is their environmental safety, stability in hard water and in the presence of iron ions, as well as a high protective aftereffect.

Corrosion tests of magnesium complexes of the OPs studied in a model solution showed that at inhibitor concentrations $C_{\text {inh }} \leq 50 \mathrm{mg} / 1$, their efficiency is almost twice 
higher than the OP efficiency, reaching $67.2 \%$ already at $C_{\text {inh }}=10 \mathrm{mg} / 1$ (Figure 3). This effect of $\mathrm{Mg}$ complexes compared to the ligands is probably caused by precipitation of a sparingly soluble hydroxide of the complex-forming cation $\left(\mathrm{Mg}^{2+}\right)$ on the metal surface, which increases the protection efficiency. In this case, the metal corrosion rate over 24 hours at $C_{\text {inh }}>100 \mathrm{mg} / 1$ is reduced three-fold on average and the efficiency reaches 87.9$91.4 \%$.

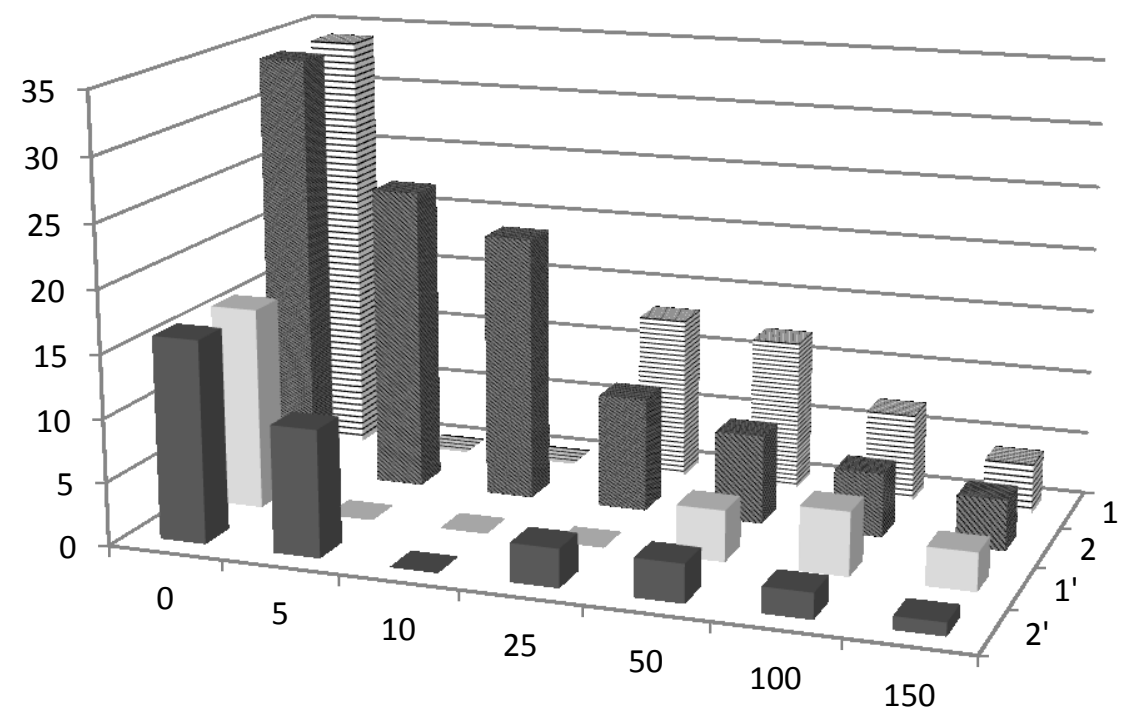

Figure 3. Dependence of St3 steel corrosion rate in model solution on the concentration of NTP:HMDTP formulation (molar ratio 4:1) (STs-105K) $\left(1,1^{\prime}\right)$ and NTP+HMDTP+Mg(II) formulation (STs-105K-M) $\left(2,2^{\prime}\right)$ and test duration, h: 1,2 - 6; $1^{\prime}, 2^{\prime}-24$.

Since 2010, researchers working in the development of reagents for stabilization water treatment pay much attention to the promising and quickly emerging approach in modern science and industry related to the nano-effect.

For example, a synthesis of metal phosphonate (DTPP) nanoparticles to be used as an inhibitor was suggested. A surfactant was used in this synthesis. Aqueous solutions of $\mathrm{Ca}$ (II) and $\mathrm{Zn}$ (II) chlorides were mixed with a neutral aqueous solution of DTPP (methylphosphonic acids) in the presence of surfactants: tetradecylammonium bromide or sodium dodecylbenzylsulfate [30].

Based on preliminary studies on the physical and chemical properties of the particles synthesized, particles of 50-200 nm size were selected that were stable for over a week in $2 \% \mathrm{KCl}$ solution at $70^{\circ} \mathrm{C}$. Such particles can penetrate into a porous medium and can potentially be used to inhibit salt in oils.

In continuation of these studies, other researchers [31] also obtained and tested nano$\mathrm{Ca}-\mathrm{DTPP}$ as a $\mathrm{CaCO}_{3}$ precipitation inhibitor. They obtained deposition/inhibition curves in real time using field emission spectroscopy. The inhibition efficiency was shown to increase in the nano-Ca-DTPP concentration range from 5.6 to $11.2 \mathrm{~g} / 1$. Nanostructured 
CaDTPP is more efficient than CaDTPP and DTPP microparticles in inhibition of $\mathrm{CaCO}_{3}$ sedimentation, including that in seawater.

Paper [32] deals with template synthesis of new $\mathrm{Zn}$-DTPP nanoparticles in the presence of silicon. An aqueous solution of $\mathrm{ZnCl}_{2}$ is adsorbed on the surface of $22 \mathrm{~nm}$ silicon particles, then a DTPP solution is added in the presence of sodium dodecylbenzylsulfate. The resulting suspension (nanofluid) of Si-Zn-DTPP is stable for 12 hours in $1 \% \mathrm{KCl}$ aqueous solution at $70^{\circ} \mathrm{C}$ and $\mathrm{pH}$ 6.7. Crystals formed from the amorphous phase during diafiltration exhibit inhibitive activity and can be used as scale inhibitors in carbonate and sandstone medium for a long time.

An interesting formulation was proposed as a corrosion inhibitor of AA2024-TK aluminum in [33]. The presence of silicate nanoparticles increases the efficiency of a formulation based on tetraethylorthosilicate and EDTP that are not nanomolecules.

On the other hand, significant progress has been achieved to date in preparation of nanostructured molecules of phosphorus-containing complexons with practically valuable properties, including, as mentioned above, the ability to efficiently inhibit scale deposition and corrosion [34].

The monolayers formed in a reaction of OPs with surface oxides are schematically presented in Figure 4 [34].
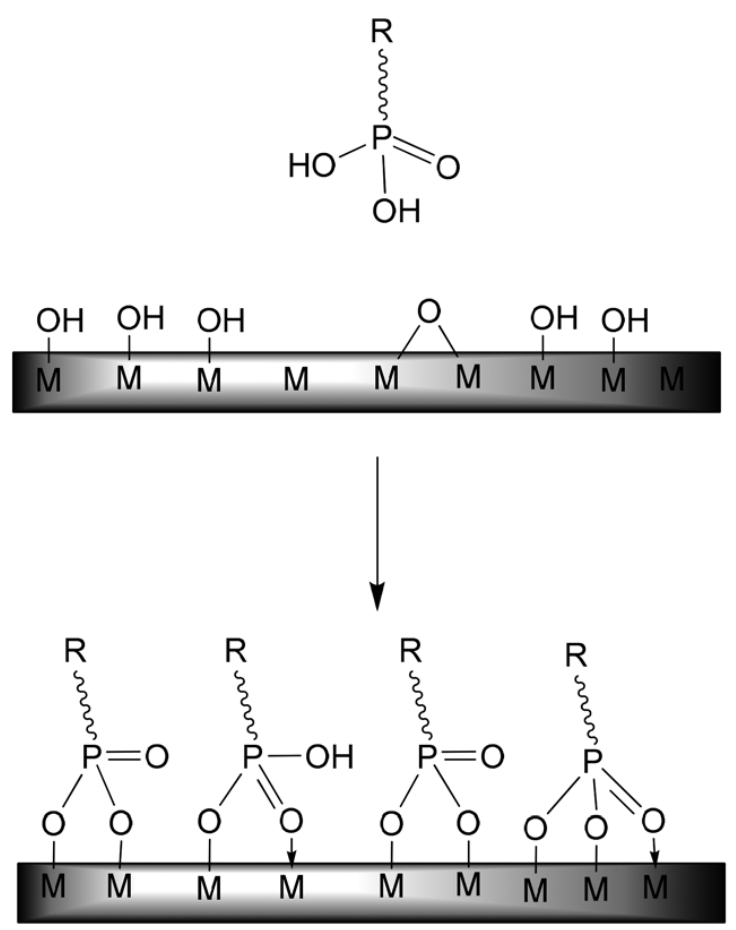

Figure 4. Schematic representation of monolayers formed upom OP interaction with a surface oxide. 


\section{Phosphonocarboxylic acids and formulations on their basis}

Studies of the well-known phosphonobutanetricarboxylic acid (PBTC) and is formulations with various additives were continued in order to enhance the inhibitive activity of the reagent against metal scaling and corrosion in water utilization equipment at various industrial enterprises.

A formulation of PBTC, $\mathrm{Zn}(\mathrm{II})$ ions, and silicate as an inhibitor of carbon steel corrosion in a solution with low chloride concentration was studied [35]. It was found by gravimetric experiments that the maximum corrosion inhibition effect $(96 \%)$ was achieved using formulations containing 50,50 and $10 \mu \mathrm{g} / 1$ of the corresponding reagents. The results of studies on the film formed on the metal surface and the solution it was immersed in, using modern methods for physical and chemical analysis (atomic absorption spectroscopy, potentiostatic polarization, electrochemical spectroscopy) and high quality instrumentation for surface studies (scanning electron and atomic force microscopes, ultrasonic Fourier transformer) were used to determine the film nature and to explain mechanistic aspects of corrosion inhibition [35].

An ascorbic acid salt was suggested as a synergistic additive to a PBTC $+\mathrm{Zn}$ (II) formulation inhibiting carbon steel corrosion in low chloride aqueous solutions [36]. It was found that a protective film stable even at $60^{\circ} \mathrm{C}$ was formed on the surface in 24 hours. The suggested formulation is efficient at lower concentrations of its components than the initial one.

Lactobionic acid (LBA) shown in Figure 5 is also considered as a synergetic additive to enhance the efficiency of a PBTC $+\mathrm{Zn}$ (II) formulation as a carbon steel corrosion inhibitor [37].

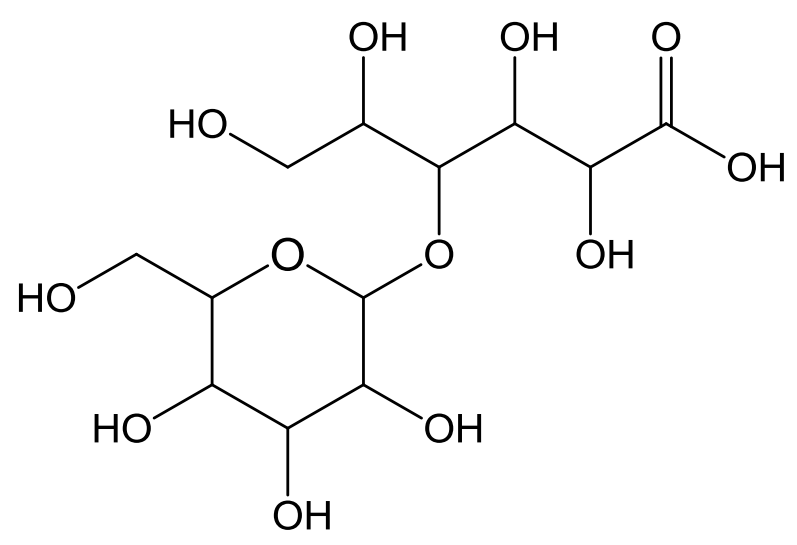

Figure 5. The chemical structure of LBA.

LBA was found to be an excellent synergist in the inhibitive formulation. Based on polarization studies in the presence of inhibitor, a protective film stable up to $60^{\circ} \mathrm{C}$ was found to be formed on the metal surface. XPS and FTIR studies of the film allowed to conclude that $\mathrm{Zn}(\mathrm{OH})_{2}$, iron oxides and hydroxides, and molecules of the inhibitor are present on the surface, probably, in the form of a $\mathrm{Zn}(\mathrm{II})-\mathrm{PBTC}-\mathrm{LBA}$ complex. Film 
formation on the metal surface was also confirmed by studies with scanning electron and atomic spectroscopy. The mechanism of corrosion inhibition was suggested.

It should be noted that LBA is a product of so-called "green" chemistry. In view of this, the authors [38] wonder whether "green" inhibitors can replace OP totally. They studied carboxymethylinulin as such a scale inhibitor, and its efficiency was significantly lower than that of OPs. However, as researchers believe, the lifetime of the "green" inhibitor studied can be modified by decreasing the $\mathrm{pH}$ of the inhibitor solution or by special methods increasing its adsorption.

PBTC is not the only inhibitor reagent containing no nitrogen. The synthesis and crystallographic characteristics of one of these compounds, a molecular linear trimer containing $\mathrm{Ca}(\mathrm{II})$ and hydroxyphosphonoacetate and with general formula $\mathrm{Ca}_{3}(\mathrm{HpaA})_{2}\left(\mathrm{H}_{2} \mathrm{O}\right)_{14}$ shown in Figure 6, were described [39].

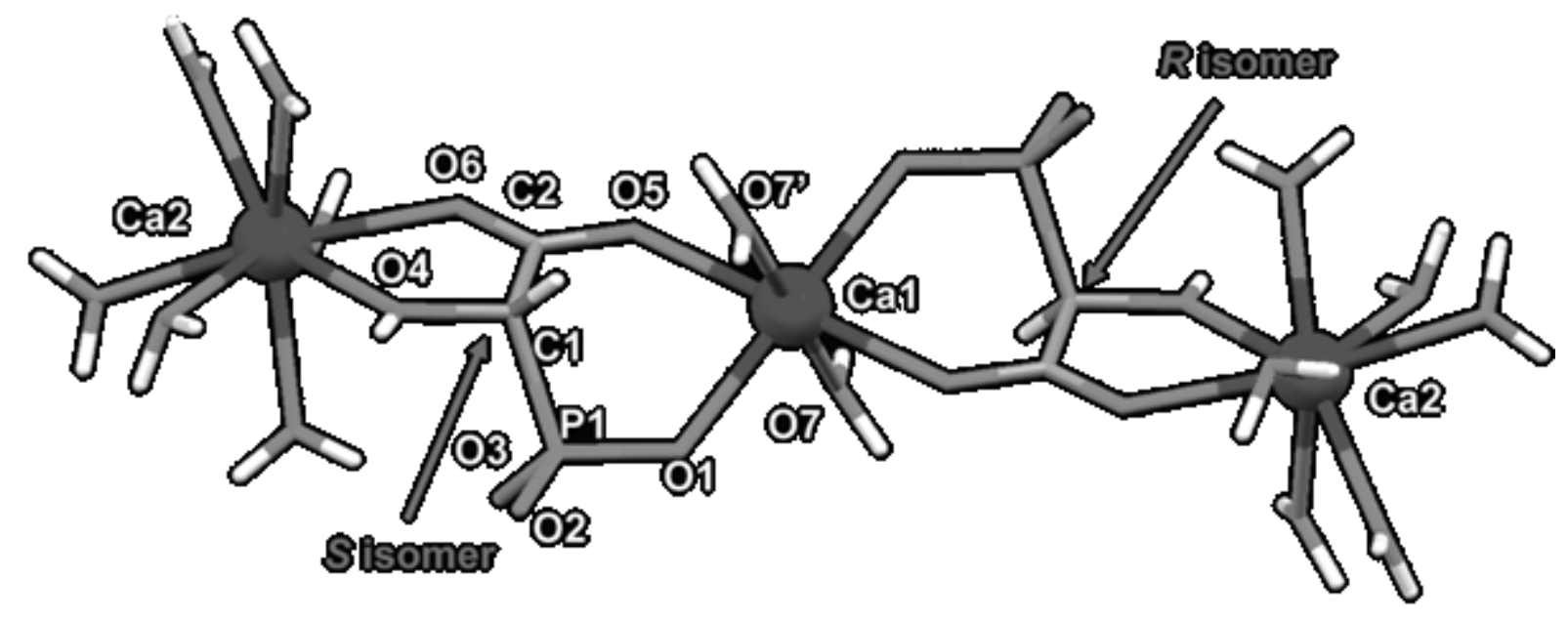

Figure 6. The structure of $\mathrm{Ca}_{3}(\mathrm{HPAA})_{2}\left(\mathrm{H}_{2} \mathrm{O}\right)_{14}$ complex.

It was found that the synthesized complex was an efficient corrosion inhibitor of carbon steel surfaces at $\mathrm{pH}$ 7.3. Using a number of research methods, it was demonstrated that a fragment of the real anticorrosive film is identical identity to the synthesized complex.

Formulations of benzotriazole derivatives with 2-phosphonoacetic acid and $\mathrm{Zn}(\mathrm{II})$, as well as of 4-phosphonobutyric acid with $\mathrm{Zn}$ (II) were studied for the first time as inhibitors of mild steel corrosion in soil water at $30-60^{\circ} \mathrm{C}$. The formulations studied were shown to have a good inhibitive activity in protection of mild steel from corrosion in soil water [40].

A newly synthesized phosphonosulfonate ligand was estimated as an inhibitor of $\mathrm{Ca}$ (II) salt (carbonate and phosphate) deposition and corrosion. A solution containing $500 \mathrm{mg} / 1 \mathrm{CaCO}_{3}$ was shown to be inhibited by $90.6 \%$ at a working reagent concentration of $4 \mathrm{mg} / \mathrm{l}$, which is significantly higher than the effect of other OPs. The degree of $\mathrm{Ca}_{3}\left(\mathrm{PO}_{4}\right)_{2}$ inhibition is $96.0 \%$ at a reagent concentration of $10 \mathrm{mg} / \mathrm{l}$. The synthesized reagent also inhibits corrosion, but it becomes more efficient in the presence of a copolymer containing a sulfonic group and zinc salts [41]. 
Along with mixed phosphonocarboxylic ligands not containing nitrogen, formulations based on similar nitrogen-containing ligands were studied as well, using bisphosphonomethylglycine (BPMG) as an example[42, 43].

A BPMG $+\mathrm{Zn}(\mathrm{II})$ formulation containing tungstate $\left(\mathrm{M}_{2} \mathrm{WO}_{4}\right)$ as a synergistic additive and efficient in neutral, weakly acidic and weakly alkaline media was suggested as an inhibitor of carbon steel corrosion in low chloride solutions. Based on the results of studies, the layer formed on steel surface was found to contain $\mathrm{Fe}$ oxide/hydroxide, $\mathrm{Zn}$ hydroxide, $\mathrm{P}, \mathrm{N}, \mathrm{O}, \mathrm{C}, \mathrm{Zn}$ and $\mathrm{W}$. Based on the results obtained, a possible mechanism of corrosion inhibition was suggested [42].

The authors [43] studied the protective film on carbon steel surface in low chloride aqueous solution in the presence of a synergistic mixture containing phosphorous acid, BPMG and Zn(II) as a corrosion inhibitor. Based on the results of XPS analysis of the film, it contained $\mathrm{Fe}, \mathrm{P}, \mathrm{N}, \mathrm{O}, \mathrm{C}$ and $\mathrm{Zn}$. Their chemical structure was Fe oxide/hydroxide, $\mathrm{Zn}(\mathrm{OH})_{2}, \mathrm{Zn}(\mathrm{II})-\mathrm{BPMG}$ as determined by further processing of the results of XPS analysis obtained. A possible mechanism of corrosion inhibition was suggested.

\section{Alkylphosphonic acids and formulations on their basis}

Alkylphosphonic acids (ALP) and formulations on their basis are also considered as corrosion inhibitors [44-47]. ALPs were studied to determine the nature of their effect on the surface of metallic iron that provides a protective anti-corrosive effect [44]. It has been shown that formation of a phosphate layer depends on the conditions created during iron passivation, and an oxide layer on the metal surface plays an important role in ensuring the protective layer stability as long as the "bare" metal surface is not suitable for bonding with phosphate. Using XPS and conversion Mössbauer spectroscopy, it was proved that an ultrathin phosphonate monolayer is present on passivated iron surface.

Propylphosphonic acid (PPA) formulations were suggested for carbon steel corrosion inhibition in neutral aqueous solutions [45, 46]. For this purpose, the authors [45] studied a PPA formulation with $\mathrm{Zn}(\mathrm{II})$, a traditional anticorrosive additive, using gravimetric, XPS, SEM, AFM, and FTIR methods. If was found that the protective surface layer contained a $\mathrm{Fe}(\mathrm{III})$ oxide/hydroxide, $\mathrm{Zn}(\mathrm{OH})_{2}$ and the [Fe(II)/(III)-Zn(II)-PPA] complex.

Pectin, a "green" inhibitor, was added to the formulation in question as a synergistic agent [46]. The results of studies of the formulation using the traditional analysis methods listed above show that pectin is an excellent synergistic agent in the formulation. The optimum concentrations of the formulation components were determined. The assumed mechanism of corrosion inhibition was presented.

A synergistic effect was identified for a formulation for corrosion inhibition of mild steel in neutral aqueous solution containing sodium ethylphosphonate, $\mathrm{Zn}(\mathrm{II})$ and molybdate. The optimum composition was determined, the proposed inhibition mechanism was discussed based on the results of studies using modern methods and equipment. 


\section{Reagents based on polymer materials}

Studies on creation and use of polymeric compounds as scale and metal corrosion inhibitors, as well as multi-component compounds based on polymers and various synergistic additives, have peen continuing in recent years [48-56]. The low toxicity of polymer reagents provides the possibility to use them under tightening of requirements for wastewater quality.

In this connection, studies of formulations based on polymers containing carboxy groups (polyacrylates, polymethacrylates, copolymers of acrylic and methacrylic acids) with OPs (NTP, HEDP, PBTC) as gypsum scale inhibitors is of interest [48]. The authors [48] managed to obtain an efficient PBTC-based synergistic formulation.

An attempt was made to control precipitations of calcium sulfate, phosphate and carbonate in industrial recirculating water systems using reagents containing no phosphorus [49]. For this purpose, a copolymer of acrylic acid with allylpolyethoxycarboxylate was synthesized and studied. The polymer obtained was proved to be an inhibitor of the mentioned $\mathrm{Ca}$ (II) salts. It is assumed that the inhibition mechanism involves formation of a soluble $\mathrm{Ca}(\mathrm{II})$ complex with the terminal carboxy group of the polymer on the surface of an inorganic particle, the solubility of which depends on the number of hydrophilic polyethylene glycol segments.

The properties of a formulation of acrylic acid, oxalic acid, and allylpolyethoxycarboxylate as a scale and corrosion inhibitor were studied. The reagent provides the maximum anticorrosive inhibitive activity (81.4\%) toward carbon steel in 3\% $\mathrm{NaCl}$ solution and inhibits $\mathrm{CaCO}_{3}$ deposition by $70.2 \%$ at a working concentration of $6 \mathrm{mg} / \mathrm{l}$ [50]. This formulation was suggested as a scale and corrosion inhibitor in cold water utilization systems.

The authors [51] suggested a new method of assessment and classification of scale inhibitors based on a study of changes in particle size using laser diffraction equipment allowing one to differentiate between crystallization nucleation and crystal growth. This method was used to estimate 4 inhibitors combined into two OP groups: EDTP and DTPP, and polymers of phosphinopolycarboxylic acid (PPA) and polyvinylsulfonate (PVS). The inhibitive activity of the tested inhibitors against $\mathrm{CaCO}_{3}$ was found to increase in the order EDTP $<$ DTPP $<$ PVA $\sim$ PPA.

For inhibition of gypsum $\left(\mathrm{CaSO}_{4} \cdot 2 \mathrm{H}_{2} \mathrm{O}\right)$ deposition, polymeric reagents were studied: poly(acrylic) (PAA) and polyaminopolyethermethylphosphonic (PAPEMP) acids and their mixture [52]. An increase in PAA concentration increases inhibition. NTP, hydroxyphosphonoacetic acid, HEDP, PBTC, and polyaminopolyethermethylphosphonic acid were studied for comparison with the polymer reagents. The best results were obtained with PAPEMP; furthermore, addition of the reagent to PAA provides a synergistic formulation.

Polyphosphonocarboxylic acid (PPCA) shown in Figure 7 was studied as an inhibitor of $\mathrm{BaSO}_{4}$ precipitation in comparison with DTPP and one of OPs in the temperature range of $50-95^{\circ} \mathrm{C}$ using various concentrations of these reagents [53]. 


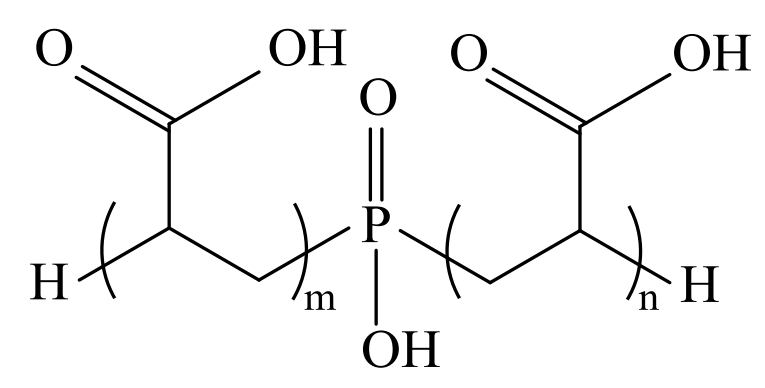

Figure 7. The chemical structure of PPCA.

Based on the tests, it was found that the efficiency of PPCA as a $\mathrm{BaSO}_{4}$ deposition inhibitor exceeds that of DTPP and OPs.

A series of polymeric materials containing diacrylate monomers (89-92.5\%) and phosphorylated monomers of methacrylates (PMM) $(1-10 \%)$ were synthesized and studied as steel corrosion inhibitors [54].

These polymeric reagents were exposed to ultraviolet irradiation, then applied to steel surface and studied by EIS. PMMs were shown to have high anticorrosive activity due to high adhesive properties of phosphorous acid, its one of its structural components, to the metal surface, compared to an esterified PMM derivative. A polymer containing $2.5 \%$ PMM has the maximum efficiency. In continuation of studies on the synthesis of new corrosion inhibitors, the authors [54] obtained a hitherto unknown phosphorus-containing reagent based on a biocompound, namely, oleic (fatty) acid, which was added to the compositions of the suggested polymeric materials. The activity of the formulations obtained was shown to be significantly higher.

Along with deposition of hardness salts, colloidal silica deposits as $\mathrm{SiO}_{2}$ are even more undesirable in water utilization systems of various industrial enterprises. They are formed in water or on various surfaces (membranes, pipes and others), where chemical cleaning is very difficult, and risky in some cases.

Some approaches for prevention of silica deposits were studied, such as ion exchange, coagulation, etc., including the use of new organic polymeric inhibitors [55]. The latter include a copolymer of adipic acid, D23O polyester (with a certain molecular mass), and diethylenetriamine (AA-OP-DETA) (Figure 8).

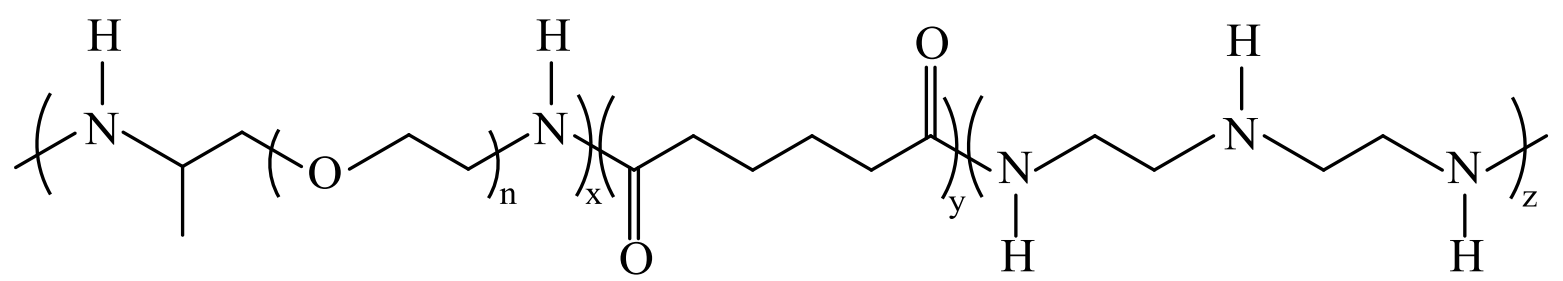

Figure 8. The chemical structure of AK-OP-DETA, where $n \sim 2.6 ; x+z=y ; x: z=1: 3$.

The authors [53] studied the effect of various copolymer concentrations shown in Figure 6 on colloidal $\mathrm{SiO}_{2}$ formation compared to OP (NTP, HEDP, EDTP, DTPP, HMDTP and PBTC) and polymeric compounds (polyacrylic, polymethacrylic, 
polyepoxysuccinic, polyaspartic acids, copolymer of acrylic and methacrylic acids). Only the new copolymer was found to have a significant inhibitive activity. Based on a study of zeta potential of colloidal silica aqueous solutions in the presence of AA-OP-DETA copolymer, it was assumed that it interacts with $\mathrm{SiO}_{2}$ particles. Based on the results of an atomic force microscopy of $\mathrm{SiO}_{2}$, it was assumed [55] that the agent studied may inhibit $\mathrm{SiO}_{2}$ polymerization which is one of the causes of the formation of colloidal silica.

Low molecular (molecular mass <10,000) polymers: polyacrylic acid (PAA), hydrolyzed anhydride of polymaleic acid (HAPA), copolymer of maleic and acrylic acids (CMAA), and phosphate ester of polyethylene glycol (PEPG) were studied as a basis for creation of multi-purpose inhibitors [56].

A study of the effect of these reagents on the crystallization of sparingly soluble salts for the classical calcium sulfate model as an example (Table 2) showed that all the reagents tested, like OPs, are scale inhibitors because they increase the specific surface energy and the nucleation reaction order, thus salt crystallization requires considerable efforts (energy consumption) to provide conditions for crystal nuclei formation. The polymer concentrations are comparable to those of OPs used for a similar purpose. The EPPG reagent with terminal phosphorus-containing groups was shown to be most efficient at minimum concentrations among the reagents studied (Table 2).

Table 2. Impact of various formulations on $\mathrm{CaSO}_{4}$ nucleation parameters.

\begin{tabular}{|c|c|c|c|c|c|}
\hline Reagent & $\begin{array}{c}\text { Reagent } \\
\text { concentration, } \\
\mathrm{mg} / \mathbf{l}\end{array}$ & $\begin{array}{c}\text { Specific surface } \\
\text { energy, } \\
\sigma, \mathbf{m J} / \mathbf{m}^{2}\end{array}$ & $\begin{array}{c}\text { Radius of a } \\
\text { critical nucleus, } \\
r, \mathbf{n m}\end{array}$ & $\begin{array}{l}\text { Order of the } \\
\text { nucleation } \\
\text { reaction, } n\end{array}$ & $\begin{array}{l}\text { Crystal growth } \\
\text { rate constant,* } \\
\mathrm{s}^{-1} \cdot 10^{4}\end{array}$ \\
\hline PAA & 100 & 6.87 & $0.36-0.54$ & 8.76 & 0.34 \\
\hline CMAA & 0.70 & 10.53 & $0.57-0.73$ & 11.57 & 0.08 \\
\hline EPPG & 0.30 & 10.96 & $0,57-0.69$ & 10.8 & 0.24 \\
\hline HAPA & 0.70 & 10.2 & $0.53-0.65$ & 8.75 & 0.10 \\
\hline IOMS-1 & 15 & 8.62 & $0.55-0.65$ & 7.14 & 7.2 \\
\hline Blank test & - & 7.8 & $0.39-0.62$ & 5.2 & 5.3 \\
\hline
\end{tabular}

* The crystal growth rate constant is indicated at concentrations: $1.85 \mathrm{mg} / \mathrm{l} \mathrm{CMAA}, 0.4 \mathrm{mg} / \mathrm{l} \mathrm{HAPA}$, $0.8 \mathrm{mg} / \mathrm{l} \mathrm{EPPG}$, and $2.0 \mathrm{mg} / \mathrm{l} \mathrm{PAA}$.

Like a majority of researchers, the authors believe that the mechanism of polymer action is not only to block crystallization micronuclei, which is typical of OPs, but also to disperse them, thus decreasing the crystal growth rate.

The results obtained show the high efficiency of polymers as corrosion inhibitors, comparable to the efficiency of zinc complexonates with OPs. However, unlike OPs, low molecular polymers can be used as such, which naturally reduces the anthropogenic impact on the environment.

In this connection, $\mathrm{Mg}$ complexes of methylphosphorylated aromatic amines obtained for the first time, namely, $(p) 1.4-$ and $(m) 1.3$-bis(aminomethyl)-benzene-bis(methyl- 
phosphonic acid) $\left(\mathrm{H}_{8} \mathrm{~L}\right)$ proposed as corrosion inhibitors [57] according to the Scheme below deserve consideration.

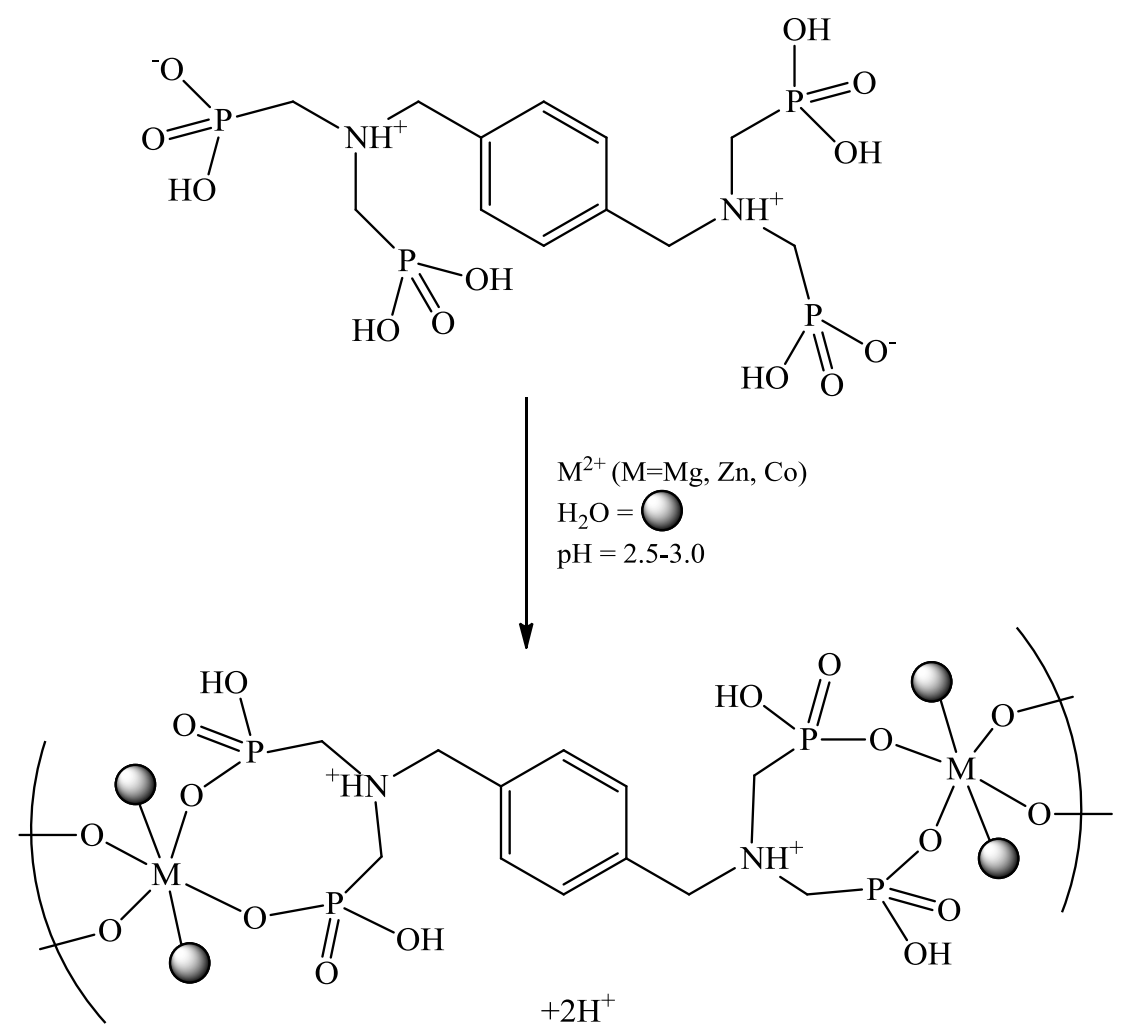

Figure 9. Interaction of $p-\mathrm{H}_{8} \mathrm{~L}$ with divalent metal cations.

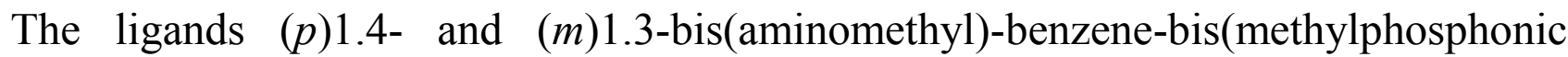
acids) $\left(\mathrm{H}_{8} \mathrm{~L}\right)$ were synthesized by the techniques described in [58].

Despite the over 40-year history of the use of OP-based formulations as metal corrosion inhibitors for water utilization equipment, studies on the mechanism of inhibitor impact still continue [59].

\section{Conclusion}

To summarize the considered results of 5-year studies on development and use of chemicals for stabilization water treatment for prevention of metal corrosion and scaling, it should be noted that OPs generally remain the most efficient compounds among complexons and their formulations. The goal of studies is to elucidate the mechanism of corrosion inhibition. Pioneering studies conducted to obtain OP compounds, new aromatic OP derivatives, and "green" chemistry compounds as inhibitors of nanostructures attract attention. 


\section{Acknowledgements}

This study was carried out with state financial support provided by the Russian Ministry of Education and Science under Subsidy Grant Agreement No.14.576.21.0017 of August 23, 2014.

\section{References}

1. N.V. Tsirulnikova, B.N. Driker, T.S. Fetisova and A.G. Tarantaev, Korroz.: mater. zashch., 2011, no. 7, 12 (in Russian).

2. L. Wang, J. Yan, Z. Lü and S. Wu, Chem. \& Bioeng., 2009, no. 1. 71.

3. D. Zuo, Contemp. Chem. Ind., 2012, 5, 466.

4. T.V. Popova, T.V. Smotrina, O.N. Denisova and N.V. Aksenova, Russ. J. Coord. Chem., 2001, 27, no. 1, 38 .

5. A. Jayswal and U. Chudasama, Turk. J. Chem., 2008, no. 32, 63.

6. I.I. Seifullina, E.E. Martsinko, G.G. Aleksandrov and V.S. Sergienko, Russ. J. Inorg. Chem., 2004, 49, no. 6, 844.

7. I.N. Shabanova, F.F. Chausov, E.A. Naimushina and I.S. Kazantseva, J. Struct. Chem., 2011, 52, 109.

8. Naimushina E.A., Chausov F.F., Kazantseva I.S., Shabanova I.N. Interaction between ZnHEDP corrosion inhibitor and a surface of carbon steel, Bull. Russ. Acad. Sci. Physics. 2013, 77, no. 3, 327.

9. Yu.V. Balaban-Irmenin, S.Yu. Petrova, L.M. Markovich and N.G. Fokina, Power Technol. Eng., 2010, 44, no. 1, 60.

10. E. Ruiz-Agudo, D. Tommaso, C.V. Putnis, N.H. Leeuw and A. Putnis, Cryst. Growth Des., 2010, 10, no. 7, 3022.

11. L. Boels, R.M. Wagterveld and G.J. Witkamp, Ultraso. Sonochem., 2011, 18, no. 5, 1225.

12. T.A. Hoang, H.M. Ang and A.L. Rohl, Desalin. Water Treat., 2011, 29, 294.

13. N.M. Dyatlova, L.T. Dityuk, R.H. Samakaev, G.F. Yaroshenko, B.I. Bihman, M.V. Rudomino, E.M. Urinovich, L.V. Krinitskaya, T.V. Balashova and N.V. Chirulina, Moscow, NIITEKHIM, 1983, pp. 25-27 (in Russian).

14. N. Labjar, S. Hajjaji, M. Lebrini, M.S. Idrissi, C. Jama and F. Bentiss, J. Mater. Environ. Sci., 2011, 2, no. 4, 2028.

15. N. Labjar, M. Lebrini, F. Bentiss, N.E. Chihib, S.E. Hajjaji and C. Jama, Mater. Chem. Phys., 2010, 119, no. 1-2, 330.

16. D.S. Kalyani, S.S. Rao, M.S. Babu, B.V.A. Rao and B. Sreedhar, Res. Chem. Intermed., 2015, 41, no. 8, 5007.

17. N. Labjar, M. Lebrini, F. Bentiss, N. Chihib, S. Hajjaji and Ch. Jama, Mater. Chem. Phys., 2010, 119, no. 1-2, 330.

18. F. Liu, X. Lu, W. Yang, J. Lu, H. Lu, X. Chang and Ch. Zhao, Desalination, 2013, 313, 18. 
19. P.B. Kosyakova, M.K. Khripun and L.A. Myund, Russ. J. Appl. Chem., 2010, 83, no. 6, 969 .

20. S. Shaw, K.S. Sorbie and L. Boak, SPE Prod. Oper., 2012, 27, no. 3, 306.

21. S. Baraka-Lokmane and K.S. Sorbie, J. Petrol. Sci. Eng., 2010, 70, no. 1-2, 10.

22. C. Rodriguez-Navarro and L.G. Benning, Elements, 2013, 9, 203.

23. M.A. Kelland, Ind. Eng. Chem. Res., 2011, 50, 5852.

24. D. Sridharan, Ch. Karthikeyan, S. Maruthamuthu, S. Manoharan and N. Palaniswamy, Ind. Eng. Chem. Res., 2013, 52, no. 46, 16175.

25. T.A. Hoang, H.M. Ang and A.L. Rohl, Aust. J. Chem, 62, no. 8, 927.

26. E. Akyol, M. Oner, E. Barouda and K.D. Demadis, Cryst. Growth Des., 2009, 9, no. $12,5145$.

27. B. Zhang, L. Zhang, F. Li, W. Hu and Ph.M. Hannam, Corros. Sci., 2010, 52, no. 12, 3883.

28. B.N. Driker, S.A. Tarasov, A.N. Obozhin, A.G. Tarantaev and N.V. Tsirul'nikova, Energy-saving and water treatment, 2010, no. 1, 4.

29. G.V. Redkina, Yu.I. Kuznetsov, L.V. Frolova and N.V. Tsirulnikova, Korroz.: mater. zashch., 2014, no. 5, 38 (in Russian).

30. P. Zhang, D. Shen, Ch. Fan, A. Kan and M. Tomson, Soc. Petrol. Eng., 2010, 15, no. 3, 610.

31. Z. Kiaei and A. Haghtalab, Desalination, 2014, 338, 84.

32. P. Zhang, A.T. Kan, C. Fan, S.N. Fan, J. Yu, H. Yu, H. Al-Saiari and M. Tomson, SPE $J ., 16$, no. 3,662 .

33. V. Dalmoro, J.H.Z. Santos, E. Santos, C. Santos and D.S. Azambuja, Corros. Sci., 2012, 60, 173.

34. G. Guerrero, J.G. Alauzun, M. Granier, D. Granier and P.H. Mutin, Dalton Trans., 2013, 42, 12569.

35. M. Prabakaran, S. Prabakaran and V. Periasamy, Res. Chem. Intermed., 2013, 39, no. $8,3507$.

36. B.V. Rao and S.S. Rao, Mater. Corros., 2010, 61, no. 4, 285.

37. S.S. Rao, B.V. Rao, S.R. Kiran and B. Sreedhar, J. Mater. Sci. Technol., 2014, 30, no. $1,77$.

38. S. Baraka-Lokmane, K. Sorbie, N. Poisson and N. Kohler, Pet. Sci. Technol., 2009, 27, no. 4, 427.

39. K.D. Demadis, M. Papadaki and I. Císařová, ACS Appl. Mater. Interf., 2010, 2, no. 7, 1814.

40. D. Gopi, M. Sherif El-Sayed, V. Sherif El-Sayed, D. Rajeswari, M. Surendiran and L. Kavitha, Ind. Eng. Chem. Res., 2014, 53, no. 11, 4286.

41. L. Zongyu, L. Hesheng and X. Wenzhou, Env. Prot. Chem. Ind., 2012, 12, no. 3, 282.

42. B.V. Rao, M.V. Rao, S.S. Rao and B. Sreedhar, J. Chem. Sci., 2010, 122, no. 4, 639. 
43. Rao B.V., Rao M.V., Rao S.S., Sreedhar B. Synergistic effect of N,Nbis(phosphonomethyl)glycine and zinc ions in corrosion control of carbon steel in cooling water systems, Chem. Eng. Commun. 2011, Vol. 198, no. 12, 1505-1529.

44. A. Paszternák, I. Felhosi, Z. Pászti, E. Kálmán and L. Kálmán, Electrochim. Acta., 2010, 55, 804 .

45. M. Prabakaran, M. Venkatesh, S. Ramesh and V. Periasamy, Appl. Surf. Sci., 2013, 276, 592.

46. M. Prabakaran, S. Prabakaran, V. Periasamy and B. Sreedhar, Res. Chem. Intermed., 2014, 1.

47. S. Rajendran, B.V. Rajendran and N. Palaniswam, Corrosion. Arabian conference; 2nd, Corrosion; 1996, 483-492.

48. Z. Amjad, Desalin. Water Treat., 2012, 37, 268.

49. Ch. Fu, Y. Fu, G. Liu, J. Huang, W. Sun and W. Wu, Ind. Eng. Chem. Res., 2011, 50, no. $18,10393$.

50. H. Wang, Y. Zhou, G. Liu, J. Huang, Q. Yao, Sh. Ma, K. Cao, Y. Liu, Y. Tian, W. Wu, W. Sun and Zh. Hu, Tens. Surf. Det., 2014, 51, no. 3, 248.

51. M.F.B. Sousa and C.A. Bertran, J. Coll. Interf. Sci., 2014, $420,57$.

52. Z. Amjad, R.T. Landgraf and J.L. Penn, Int. J. Corros. Scale Inhib., 2014, 3, no. 1, 35. doi: $10.17675 / 2305-6894-2014-3-1-035-047$

53. A. BinMerdhah, J. Petrol. Sci. Eng., 2012, 90-91, 124.

54. F. Millet, R. Auvergne, S. Caillol, G. David, A. Manseri and N. Pébère, Prog. Org. Coat., 2014, 77, 285.

55. B. Zhang, Y. Chen and F. Li, Coll. Surf. A: Physicochem. Eng. Aspects, 2011, 385, 11.

56. B.N. Driker, S.A. Tarasov, A.G. Tarantaev and A.N. Obozhin, Energy Saving and Water Treat., 2010, no. 6, 15.

57. R.M.P. Colodrero, G.K. Angeli, M. Bazaga-Garcia， P. Olivera-Pastor, D. Villemin, E.R. Losilla, E.Q. Martos, G.B. Hix, M.A.G. Aranda, K.D. Demadis and A. Cabeza, Inorg. Chem., 2013, 52, no. 15, 8770.

58. D. Villemin, B. Moreau, A. Elbilali, M. Didi, M. Kaid and P. Jaffres, Phosphorus, Sulfur Silicon Relat. Elem., 2010, 185, 2511.

59. R. Touir, N. Dkhireche, M. Touhami, M. Sfaira, O. Senhaji, J.J. Robin, B. Boutevin and M. Cherkaoui, Mater. Chem. Phys., 2010, 122, 1. 